\title{
Excess Purine Degradation in Exercising Muscles of Patients with Glycogen Storage Disease Types V and VII
}

\author{
Ikuo Mineo, Norio Kono, Takao Shimizu, Naoko Hara, Yuya Yamada, Seiichi Sumi, Kyohei Nonaka, and Seiichiro Tarui \\ The Second Department of Internal Medicine, Osaka University Medical School, Fukushima-ku, Osaka 553, Japan
}

\section{Abstract}

To investigate purine catabolism in exercising muscles of patients with muscle glycogen storage disease, we performed ischemic forearm exercise tests and quantitated metabolites appearing in cubital venous blood. Two patients with glycogen storage disease type $V$ and three with glycogen storage disease type VII participated in this study.

Basal lactate concentrations lowered in every patient with glycogen storage disease type $\mathrm{V}$ or type VII. Two patients with glycogen storage disease type VII, who had markedly elevated concentrations of serum uric acid (14.3 and $11.9 \mathrm{mg} /$ dl, respectively), showed high basal concentrations of ammonia (118 and $79 \mu \mathrm{mol} / \mathrm{liter}$, respectively; $23 \pm 4 \mu \mathrm{mol} / \mathrm{liter}$ in healthy controls) and of hypoxanthine (23.4 and $20.4 \mu \mathrm{mol} / \mathrm{liter}$, respectively; $2.0 \pm 0.4 \mu \mathrm{mol} / \mathrm{liter}$ in healthy controls). Other patients showed near normal measurements of these metabolites.

After forearm exercise, ammonia, inosine, and hypoxanthine levels increased greatly in every patient studied, in contrast with the lack of increase in lactate levels. The incremental area under the concentration curves for venous ammonia was 13-fold greater in the glycogen storage disease group than in controls $(1,120 \pm 182$ vs. $83 \pm 26 \mu \mathrm{mol} \cdot \mathrm{min} / \mathrm{liter})$. The incremental areas of inosine and hypoxanthine were also greater in the glycogen storage disease group (29.2 \pm 7.2 vs. $0.4 \pm 0.1$ and 134.6 \pm 23.1 vs. $14.9 \pm 3.2 \mu \mathrm{mol} \cdot \mathrm{min} / \mathrm{liter}$, respectively). The incremental areas of ammonia in controls and in glycogen storage disease patients strongly correlated with those of hypoxanthine $(r=0.984, n=11, P<0.005)$.

These findings indicated that excess purine degradation occurred in the exercising muscles of patients with glycogen storage disease types $\mathrm{V}$ and VII, and suggested that the ATP pool in the exercising muscles may be deranged because of defective glycogenolysis or glycolysis.

\section{Introduction}

Glycogen storage disease (GSD) ${ }^{1}$ type V (muscle phosphorylase deficiency or McArdle disease) (1) and type VII (phosphofructokinase deficiency or Tarui disease) (2) are muscle-energy diseases affecting glycogenolysis and glycolysis, respectively (3). Patients with these diseases have common muscular symptoms such as easy fatigability, stiffness, and pain on muscular

Address reprint requests to Dr. Mineo.

Received for publication 11 December 1984 and in revised form 1 April 1985.

1. Abbreviation used in this paper: GSD, glycogen storage disease.

J. Clin. Invest.

(C) The American Society for Clinical Investigation, Inc.

0021-9738/85/08/0556/05 \$1.00

Volume 76, August 1985, 556-560 exertion when energy demands are increased. The symptoms are considered to be due to defective ATP generation in intramuscular glycolysis, which may lead to a critical shortage of intramuscular ATP. However, such ATP depletion has not been demonstrated in contractured muscles from patients with GSD type V $(4,5)$. On the other hand, exercised, cramped muscle from an animal model of defective muscle glycolysis showed marked depletion of ATP (6).

Vigorous exercise normally drives the catabolic reactions of adenine nucleotides in muscle and their metabolites appear in circulating blood (Fig. 1). Since 1928 it has been known that ammonia arises in muscle by the deamination of AMP into IMP by the action of adenylate deaminase (EC 3.5.4.6) $(7,8)$. Ammonia readily passes through the cell membrane, but most of the IMP may be preserved in the muscle and reconverted to AMP via adenylsuccinate (purine nucleotide cycle) (8). On the other hand, some of the IMP molecule may be broken down into its nucleoside, inosine, and its base, hypoxanthine $(9,10)$. These substances, which serve as precursors of uric acid, also can be detected in circulating blood, since the muscle cell membrane is relatively permeable to them. Although the physiological significance of intramuscular purine catabolism has not been thoroughly clarified, many data suggest that it is closely related to energy metabolism in exercising muscle $(8,10-16)$.

The present study was thus designed to investigate purine catabolism in the exercising muscles of patients with GSD types $\mathrm{V}$ and VII.

\section{Methods}

Patients. Two patients with GSD type V (patients 1 and 2) and three with type VII (patients 3-5) were studied. Patient 1, a 26-yr-old woman, was presented to our clinic because of her high plasma creatine kinase level at medical examination. The clinical details have been described elsewhere (17). Patient 2, a 29-yr-old woman, was referred to our clinic from Senboku National Hospital, Osaka. These two patients belonged to unrelated families. Patient 3, a 44-yr-old man, and patient 4, a 43-yr-old man, are brothers with GSD type VII from the family described previously (2). Patient 5, a 20-yr-old man with GSD type VII, belonging to the second family in Japan, was referred to our laboratory from Yokosuka Mutual Aid Hospital, Yokosuka, for biochemical analyses. Careful tracing of their histories revealed several episodes of a second wind phenomenon (18) in both cases of GSD type $\mathrm{V}$ but no evidence of the phenomenon in any of the GSD type VII cases. Definite diagnoses were established through enzymatic analyses of muscle biopsy specimens, and these data have been described elsewhere $(2,17,19)$. A control group of unconditioned, healthy volunteers consisted of five men (19-38 yr old) and one woman ( $28 \mathrm{yr}$ old). Informed consent was obtained from each of the patients and control subjects before the study.

Procedure. After bed rest for at least $30 \mathrm{~min}$, ischemic forearm exercise tests were carried out, according to a procedure described previously (19). To determine lactate, inosine, and hypoxanthine levels, blood was deproteinized by adding $2 \mathrm{vol}$ of cold $6 \%$ (vol/vol) perchloric 


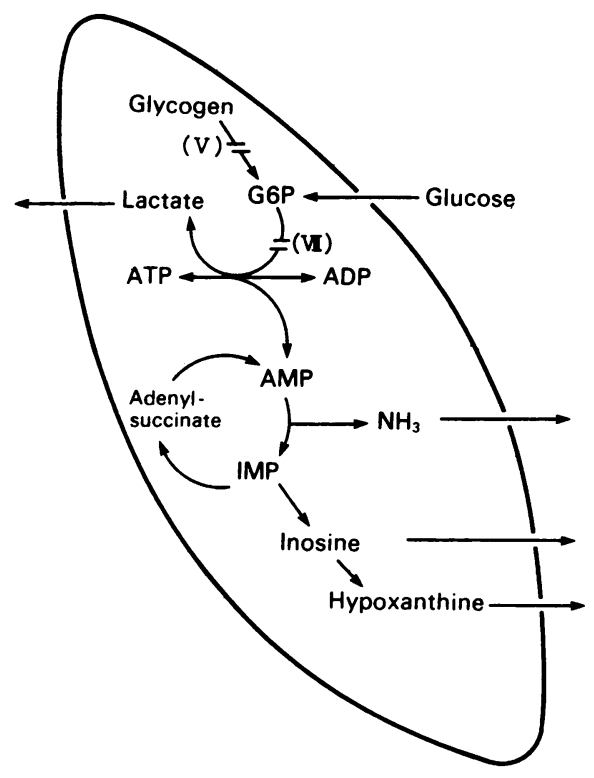

Figure 1. Reactions for purine catabolism and glycolysis in muscle. G6P, glucose-6-phosphate; (V) and (VII), metabolic block in GSD type V and type VII, respectively.

acid immediately after sampling. The extract was stored at $-80^{\circ} \mathrm{C}$ until assayed. For plasma ammonia estimation, blood samples were collected in iced tubes containing crystallized heparin, and the assay was done within a few hours.

Assay. Blood lactate (20), plasma ammonia (21), and serum uric acid (22) were assayed enzymatically. Inosine and hypoxanthine were separated and quantitated by high performance liquid chrọmatography. The high performance liquid chromatography system (model 302, 802, 811, and 111B; Gilson Medical Electronics, Inc., Middleton, WI) with a microsorb $\mathrm{C} 18$ reversed-phase column (Rainin Instrument Co. Inc., Woburn, MA) was used. Chromatographic conditions were established according to the method of Zakaria et al. (23), the low-strength eluant consisting of a $20-\mathrm{mmol} /$ liter potassium phosphate buffer (pH 5.7). A $60 \%$ (vol/vol) methanol-water mixture was used as the high strength eluant. The gradient was linear from 0 to $40 \%$ of the high strength eluant in $35 \mathrm{~min}$. The elution peaks were identified by comparing retention times with known external standards and relative absorbances at 254:280 $\mathrm{nm}$. Inosine and hypoxanthine for standard solution were purchased from Sigma Chemical Co., St. Louis, MO. Other chemicals were obtained from Wako Pure Chemical Industries, Ltd., Higashi-ku, Osaka, Japan.

Statistics. Differences in mean values between the two groups were studied by the unpaired $t$ test. A possible correlation between a pair of parameters was sought by linear regression analysis.

\section{Results}

The concentrations of venous lactate, ammonia, inosine, hypoxanthine, and uric acid in the basal state (at $0 \mathrm{~min}$ ) are given in Table I. Basal lactate lowered in every patient with GSD type V or VII. The mean value in the GSD group was significantly smaller than that in controls $(544 \pm 37$ vs. $882 \pm 54$ $\mu$ mol/liter, respectively, $P<0.005$ ). Two patients with GSD type VII (patients 3 and 4) had very high concentrations of ammonia (118 and $79 \mu \mathrm{mol} /$ liter, respectively), hypoxanthine (23.4 and $20.4 \mu \mathrm{mol} / \mathrm{liter}$, respectively), and uric acid (14.3 and $11.9 \mathrm{mg} / \mathrm{dl}$, respectively). Other patients with GSD type V (patients 1 and 2) and type VII (patient 5) showed near normal measurements.

The 2-min handgrip exercise caused no appreciable increase of venous lactate in any patient with GSD type V or VII (Fig. 2 ), indicating that intramuscular glycolysis never proceeded in vivo.

Venous ammonia levels increased after forearm exercise. In the control group, maximal increases of ammonia had a significant positive correlation with increases of lactate ( $r$ $=0.841, P<0.05$; data not shown). An exaggerated increase of ammonia was observed in every patient studied (Fig. 3), in contrast with the lack of lactate increase. The mean incremental area under the concentration curves of venous ammonia, calculated from the data in Fig. 3, was 13-fold greater in the GSD group than in the control group $(1,120 \pm 182$ vs. $83 \pm 26$ $\mu \mathrm{mol} \cdot \mathrm{min} /$ liter) (Table II).

Venous inosine levels increased very little in the controls after forearm exercise, whereas the increase was prominent in patients with both types of GSD (Fig. 4). In patients with GSD type VII, inosine increased exponentially, with the concentrations at $8 \mathrm{~min}$ being $>50$ times higher than basal concentrations. The incremental area of inosine in each of the GSD patients was significantly greater than in any individual control subject, and the mean value in the GSD group was 73 times that in the control group $(29.2 \pm 7.2$ vs. $0.4 \pm 0.1 \mu \mathrm{mol} \cdot \mathrm{min} / \mathrm{liter})$ (Table II).

Venous hypoxanthine levels were also much increased after forearm exercise in both types of GSD (Fig. 5). The mean incremental area of hypoxanthine in the GSD group was about nine times the control value $(134.6 \pm 23.1$ vs. $14.9 \pm 3.2$ $\mu \mathrm{mol} \cdot \mathrm{min} / \mathrm{liter}$ ) (Table II). The incremental areas of ammonia in the control subjects and in the patients were plotted against those of hypoxanthine (Fig. 6), revealing a strong correlation between the two parameters $(r=0.984, n=11, P<0.005)$. This suggests that hypoxanthine was produced in proportion to the rate of AMP deamination (Fig. 1).

Table I. Basal Concentrations of Venous Lactate, Ammonia, Inosine, Hypoxanthine, and Uric Acid in Muscle GSD

\begin{tabular}{llllrr} 
& Lactate & Ammonia & Inosine & Hypoxanthine & $\begin{array}{c}\text { Uric } \\
\text { Acid }\end{array}$ \\
\hline Patient 1 (type V) & 572 & 35 & 0.6 & 2.3 & 3.4 \\
Patient 2 (type V) & 502 & 27 & 0.5 & 1.2 & 4.4 \\
Patient 3 (type VII) & 479 & 118 & 0.6 & 23.4 & 14.3 \\
Patient 4 (type VII) & 489 & 79 & 0.3 & 20.4 & 7.9 \\
Patient 5 (type VII) & 676 & 34 & 0.4 & 2.6 & 5.4 \\
Controls ( $n=6$ ), mean \pm SE & $882 \pm 54$ & $23 \pm 4$ & $0.7 \pm 0.1$ & 5.3 & 0.6 \\
\hline
\end{tabular}

Each value is represented in micromoles per liter plasma (ammonia) or blood (lactate, hypoxanthine, inosine) or milligrams per deciliter serum (uric acid). 


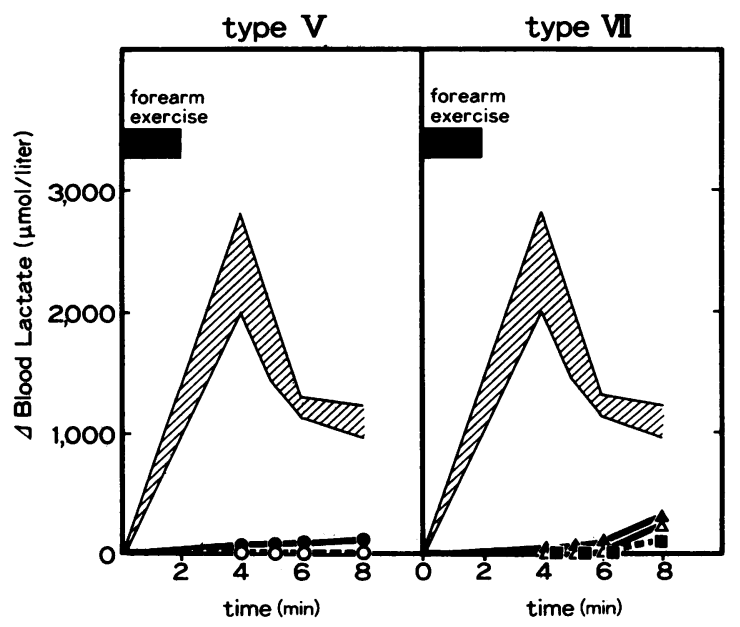

Figure 2. Increase in venous lactate concentration after ischemic forearm exercise in patients with GSD type V (patient 1, •; patient 2, O) and type VII (patient 3, ; patient 4, $\Delta$; patient 5, ). Forearm exercise was done by squeezing a hand dynamometer once every second for $2 \mathrm{~min}$. Blood was drawn from an antecubital vein five times just before the start of exercise $(0 \mathrm{~min})$ and $4,5,6$, and $8 \mathrm{~min}$ after exercise started. The shaded area indicates the mean $\pm \mathrm{SE}$ in healthy controls $(n=6)$.

Venous uric acid levels were not significantly changed after forearm exercise in either group (data not shown).

\section{Discussion}

Ammonia arises in exercising muscle from AMP deamination into IMP, the first step of the purine nucleotide cycle (Fig. 1). This study showed the exaggerated increase in venous ammonia levels in patients with types V and VII GSD after exercise (Fig. 3), thus providing the first evidence of an excess production of ammonia in GSD type VII. A similar increase in ammonia levels after exercise has already been shown in a patient with GSD type V (24). Moreover, a study on phosphorylase kinase-

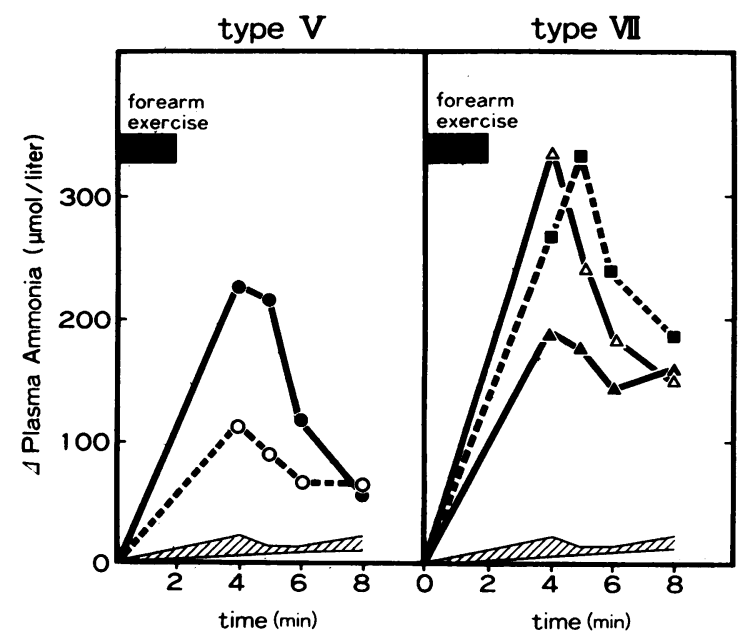

Figure 3. Increase in venous ammonia concentration after ischemic forearm exercise in patients with GSD type $\mathbf{V}$ (patient 1, $\bullet$; patient 2 , O) and type VII (patient 3, $\Delta$; patient 4, $\Delta$; patient 5, $\square$ ). The shaded area indicates the mean $\pm \mathrm{SE}$ in healthy controls $(n=6)$.
Table II. Incremental Areas of Venous

Ammonia, Inosine, and Hypoxanthine after Forearm

Exercise in Patients with Muscle GSD

\begin{tabular}{llll}
\hline & $\Sigma$ Ammonia & $\Sigma$ Inosine & $\Sigma$ Hypoxanthine \\
\hline & & & \\
Patient 1 (type V) & 1,021 & 32.4 & 153.2 \\
Patient 2 (type V) & 535 & 5.8 & 51.2 \\
Patient 3 (type VII) & 1,032 & 45.5 & 121.2 \\
Patient 4 (type VII) & 1,463 & 41.4 & 166.3 \\
Patient 5 (type VII) & 1,551 & 21.1 & 181.1 \\
Mean \pm SE & $1,120 \pm 182^{*}$ & $29.2 \pm 7.2 \ddagger$ & $134.6 \pm 23.1^{*}$ \\
Controls ( $n=6$ ), & & & \\
$\quad$ mean \pm SE & $83 \pm 26$ & $0.4 \pm 0.1$ & $14.9 \pm 3.2$ \\
\hline
\end{tabular}

The incremental areas $(\Sigma)$ were estimated as the areas under the curves of venous ammonia, inosine, and hypoxanthine in Figs. 3, 4, and 5, respectively. Data represent micromoles times minutes per liter. The symbols $(*$, $\ddagger)$ indicate significant differences $([*] P<0.001$, $[\ddagger] P<0.005)$ from control values.

deficient mice revealed enhanced accumulation of IMP in exercising muscle (25). These findings suggest that purine catabolism is altered in the exercising muscles of patients with muscle-energy diseases affecting glycogenolysis and glycolysis.

Ammonia production by muscle is known to be greatest during intense exercise (26) or tetanic muscle stimulation (27), when the rate of ATP utilization may exceed the rate of ATP resynthesis. Meyer et al. (28) and Sabina et al. (15) recently demonstrated that the amount of IMP produced in exercising muscle is stoichiometric with the decrease in ATP. According to these observations, the exaggerated AMP deamination in patients with muscle GSD implies a critical shortage of ATP in their exercising muscles. Since the ATP pool in muscle is large and exercise performance in GSD is very limited, exerciseinduced ATP depletion can hardly be detected $(4,5)$. Adenylate deaminase, an allosteric enzyme whose enzyme activity is regulated by many factors (e.g., $\mathrm{pH}$, purine nucleotides, alkali metal ions, inorganic phosphate, enzyme binding to myosin, etc.; $8,29,30$ ), is inhibited by ATP (at a low concentration),

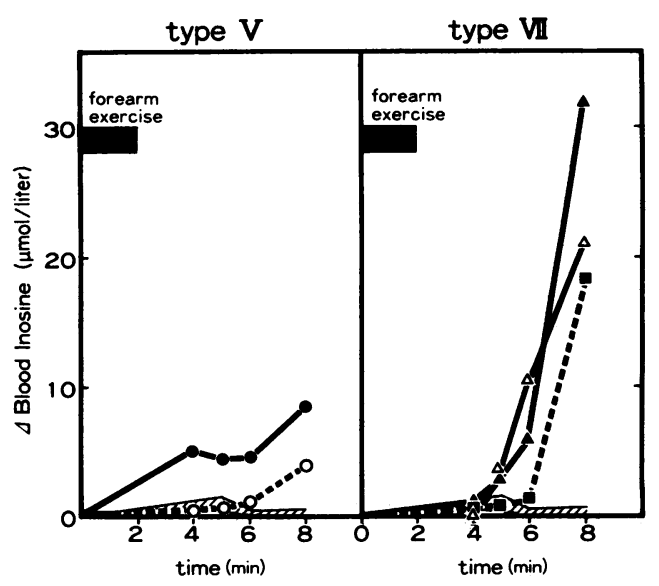

Figure 4. Increase in venous inosine concentration after ischemic forearm exercise in patients with GSD type $\mathrm{V}$ (patient 1, ๑; patient 2, 0 ) and type VII (patient 3, $\Delta$; patient $4, \Delta$; patient $5, \square)$. The shaded area indicates the mean $\pm \mathrm{SE}$ in healthy controls $(n=6)$. 


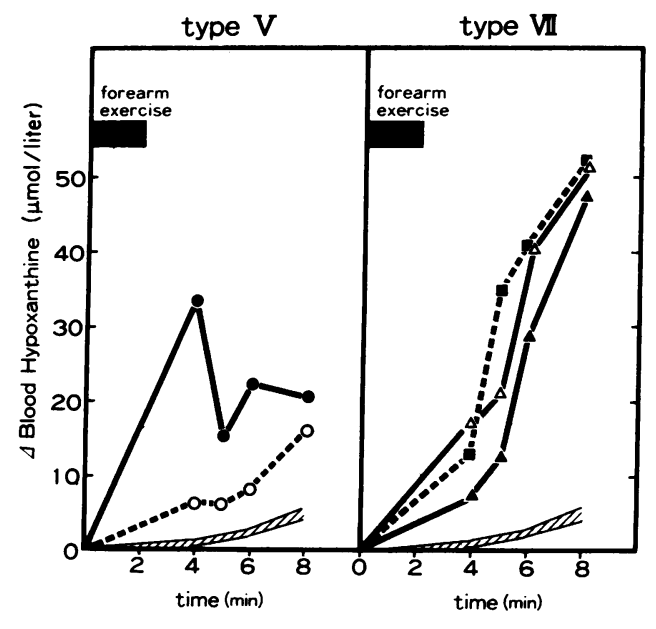

Figure 5. Increase in venous hypoxanthine concentration after ischemic forearm exercise in patients with GSD type V (patient 1, ๑; patient 2, 0 ) and type VII (patient 3, $\Delta$; patient $4, \Delta$; patient 5, $\bullet$ ). The shaded area indicates the mean $\pm \mathrm{SE}$ in healthy controls $(n=6)$.

but activated by ADP and AMP. In muscle GSD, net ATP hydrolysis must lead to a heavy accumulation of ADP and AMP, due to the defect of ATP generation in glycolysis (Fig. 1). This derangement of adenine nucleotides may possibly be responsible for the exaggerated AMP deamination.

In every patient with GSD type V or VII, forearm exercise led to an exaggerated increase in venous inosine (Fig. 4) and hypoxanthine (Fig. 5) as well as ammonia levels. Excess hypoxanthine release from exercising muscle has been reported in a patient with GSD type V (31). In the present study, we showed a strong correlation between ammonia and hypoxanthine responses to forearm exercise (Fig. 6), suggesting that increased AMP deamination may accelerate the subsequent reactions of IMP breakdown to inosine, thereby leading to the formation of hypoxanthine (Fig. 1). Thus, the more IMP produced, the more inosine and hypoxanthine formed, both of which can permeate the muscle cell membrane and appear in circulating blood.

According to recent reports, some patients with GSD type VII (32-34) and muscle phosphoglycerate mutase deficiency

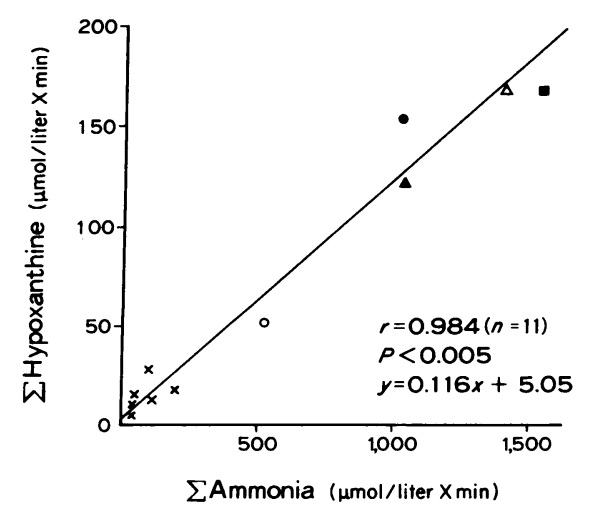

Figure 6. Relation of the incremental area of venous ammonia ( $\Sigma$ ammonia) to that of hypoxanthine ( $\Sigma$ hypoxanthine) in the forearm exercise tests. Data from Table II were used: control subjects $(x)$, patient $1(\bullet)$, patient $2(0)$, patient $3(\Delta)$, patient $4(\Delta)$, and patient 5 (๘).
(35) develop hyperuricemia or gouty arthritis. Our patients with GSD type VII (patients 3 and 4) also exhibited marked hyperuricemia, and interestingly, the levels of venous ammonia and hypoxanthine were conspicuously high even in the basal state (Table I). We are now studying the etiological contribution of excess purine degradation in exercising muscle to the development of the hyperuricemia.

The basal concentration of venous lactate was significantly lowered in every patient studied (Table I). We previously demonstrated that glycolytic intermediates in resting muscles from patients with GSD types V and VII showed a distinct crossover at each of the phosphorylase and the phosphofructokinase steps $(2,17,36)$, suggesting that the block in muscle exists even at rest. The lowered basal lactate levels were probably due to a defect of lactate production in muscle and thus may be a sign suggestive of muscle-energy disease affecting glycogenolysis or glycolysis. In addition, the exaggerated responses of ammonia, inosine, and hypoxanthine to exercise, as well as the unresponsiveness of lactate $(1,2,35,37,38)$, may be useful indicators in screening patients for disturbed intramuscular glycogenolysis and glycolysis.

In the present study, we demonstrated the excess release of ammonia, inosine, and hypoxanthine (ATP catabolites) from exercising muscles in patiento with GSD types $V$ and VII. We considered a possible derangement of the ATP pool due to defective intramuscular glycogenolysis or glycolysis.

\section{Acknowledgments}

The authors are grateful to Dr. W. Koyama and Dr. M. Kanayama (Yokosuka Mutual Aid Hospital) and Dr. N. Ueda (Senboku National Hospital) for participating in the study of their patients.

This study was supported in part by grants-in-aids for scientific research $(59480214,59480255,59570484$, and 59870040) and special project research (58105008) from the Ministry of Education, Science and Culture of Japan, and by a basic research grant from the Muscular Dystrophy Association of the United States.

\section{References}

1. McArdle, B. 1951. Myopathy due to a defect in muscle glycogen breakdown. Clin. Sci. (Lond.). 10:13-33.

2. Tarui, S., G. Okuno, Y. Ikura, T. Tanaka, M. Suda, and M. Nishikawa. 1965. Phosphofructokinase deficiency in skeletal muscle: a new type of glycogenosis. Biochem. Biophys. Res. Commun. 19:517523.

3. Beaudet, A. L. 1983. The glycogen storage disease. In Harrison's Principles of Internal Medicine. R. G. Petersdorf, R. D. Adams, E. Braunwald, K. J. Isselbacher, J. B. Martin, and J. D. Wilson, editors. McGraw-Hill Inc., New York. Tenth ed. 539-545.

4. Rowland, L. P., S. Araki, and P. Carmel. 1965. Contracture in McArdle's disease. Arch. Neurol. 13:541-544.

5. Ross, B. D., G. K. Radda, D. G. Gadian, G. Rocker, M. Esiri, and J. Falconer-Smith. 1981. Examination of a case of suspected McArdle's syndrome by ${ }^{31} \mathrm{P}$ nuclear magnetic resonance. $N$. Engl. $J$. Med. 304:1338-1342.

6. Brumback, R. A., J. W. Gerst, and H. R. Knull. 1983. High energy phosphate depletion in a model of defective muscle glycolysis. Muscle Nerve. 6:52-55.

7. Embden, G., and H. Wassermeyer. 1928. Über die Bedeutung der Adenylsäure für die Muskelfunktion. 5. Die Quelle des bei der Kontraktion gebildeten Ammonaks. Z. Physiol. Chem. 179:226-237.

8. Lowenstein, J. M. 1972. Ammonia production in muscle and other tissues: the purine nucleotide cycle. Physiol. Rev. 52:382-414. 
9. Sutton, J. R., C. J. Toews, G. R. Ward, and I. H. Fox. 1980. Purine metabolism during strenuous muscular exercise in man. Metab. Clin. Exp. 29:254-260.

10. Patterson, V. H., K. K. Kaiser, and M. H. Brooke. 1983. Exercising muscle does not produce hypoxanthine in adenylate deaminase deficiency. Neurology. 33:784-786.

11. Tornheim, K., and J. M. Lowenstein. 1973. The purine nucleotide cycle: III. Oscillations in metabolite concentrations during the operation of cycle in muscle extracts. J. Biol. Chem. 248:26702677.

12. Aragon, J. J., K. Tornheim, and J. M. Lowenstein. 1980. On a possible role of IMP in the regulation of phosphorylase activity in skeletal muscle. FEBS (Fed. Eur. Biochem. Soc.) Lett. 117:K56-K64.

13. Aragon, J. J., K. Tornheim, M. N. Goodman, and J. M. Lowenstein. 1981. Replenishment of citric acid cycle intermediates by the purine nucleotide cycle in rat skeletal muscle. Curr. Top. Cell Regul. 18:131-149.

14. Hochachka, P. W., and T. P. Mommsen. 1983. Protons and anaerobiosis. Science (Wash. DC). 219:1391-1397.

15. Sabina, R. L., J. L. Swain, C. W. Olanow, W. G. Bradley, W. N. Fishbein, S. DiMauro, and E. W. Holmes. 1984. Myoadenylate deaminase deficiency. Functional and metabolic abnormalities associated with disruption of the purine nucleotide cycle. J. Clin. Invest. 73:720730.

16. Swain, J. L., J. J. Hines, R. L. Sabina, O. L. Harbury, and E. W. Holmes. 1984. Disruption of the purine nucleotide cycle by inhibition of adenylosuccinate lyase produces skeletal muscle dysfunction. J. Clin. Invest. 74:1422-1427.

17. Kono, N., I. Mineo, T. Shimizu, S. Sumi, J. Kang, K. Nonaka, and S. Tarui. 1984. Metabolic basis of improved exercise tolerance: muscle phosphorylase deficiency after glucagon administration. Neurology. 34:1471-1476.

18. Howell, R. R., and J. C. Williams. 1983. The glycogen storage diseases. In The Metabolic Basis of Inherited Disease. J. B. Stanbury, J. B. Wyngaarden, D. S. Fredrickson, J. L. Goldstein, and M. S. Brown, editors. McGraw-Hill Inc., New York. Fifth ed. 157-159.

19. Mineo, I., N. Kono, T. Shimizu, S. Sumi, K. Nonaka, and S. Tarui. 1984. A comparative study on glucagon effect between McArdle disease and Tarui disease. Muscle Nerve. 7:552-559.

20. Gutmann, I., and A. W. Wahlefeld. 1974. L-lactate determination with lactate dehydrogenase and NAD. In Methods of Enzymatic Analysis. H. U. Bergmeyer, editor. Academic Press, New York. $1464-$ 1468.

21. van Anken, H. C., and M. E. Schiphorst. 1974. A kinetic determination of ammonia in plasma. Clin. Chim. Acta. 56:151-157.

22, Lorentz, K., and W. Berndt. 1967. Enzymic determination of uric acid by a colorimetric method. Anal. Biochem. 18:58-63.

23. Zakaria, M., P. R. Brown, M. P. Farnes, and B. E. Barker. 1982. HPLC analysis of aromatic amino acids, nucleosides, and bases in plasma of acute lymphocytic leukemics on chemotherapy. Clin. Chim. Acta. 126:69-80.

24. Rumpf, K. W., H. Wagner, H. Kaiser, H. M. Meinck, H. H.
Goebel, and F. Scheler. 1981. Increased ammonia production during forearm ischemic work test in McArdle's disease. Klin. Wochenschr. 59:1319-1320.

25. Rahim, Z. H. A., D. Perrett, G. Lutaya, and J. R. Griffiths. 1980. Metabolic adaptation in phosphorylase kinase deficiency. Changes in metabolite concentrations during tetanic stimulation of mouse leg muscles. Biochem. J. 186:331-341.

26. Wilkerson, J. E., D. L. Batterton, and S. M. Horvath. 1977. Exercise-induced changes in blood ammonia levels in humans. Eur. $J$. Appl. Physiol. Occup. Physiol. 37:255-263.

27. Meyer, R. A., and R. L. Terjung. 1979. Differences in ammonia and adenylate metabolism in contracting fast and slow muscle. Am. J. Physiol. 237:C111-C118.

28. Meyer, R. A., G. A. Dudley, and R. L. Terjung. 1980. Ammonia and IMP in different skeletal muscle fibers after exercise in rats. J. Appl. Physiol. 49:1037-1041.

29. Wheeler, T. J., and J. M. Lowenstein. 1979. Adenylate deaminase from rat muscle. Regulation by purine nucleotides and orthophosphate in the presence of $150 \mathrm{mM} \mathrm{KCl}$. J. Biol. Chem. 254:8994-8999.

30. Shiraki, H., S. Miyamoto, Y. Matsuda, E. Momose, and H. Nakagawa. 1981. Possible correlation between binding of muscle type AMP deaminase to myofibrils and ammoniagenesis in rat skeletal muscle on electrical stimulation. Biochem. Biophys. Res. Commun. 100:1099-1103.

31. Brooke, M. H., V. H. Patterson, and K. K. Kaiser. 1983. Hypoxanthine and McArdle disease. A clue to metabolic stress in the working forearm. Muscle Nerve. 6:204-206.

32. Agamanolis, D., A. D. Askari, S. DiMauro, A. Hays, K. Kumar, M. Lipton, and A. Raynor. 1980. Muscle phosphofructokinase deficiency: two cases with unusual polysaccharide accumulation and immunologically active enzyme protein. Muscle Nerve. 3:456-467.

33. Vora, S., M. Davidson, C. Seaman, A. F. Miranda, N. A. Noble, K. R. Tanaka, E. P. Frenkel, and S. DiMauro. 1983. Heterogeneity of the molecular lesions in inherited phosphofructokinase deficiency. J. Clin. Invest. 72:1995-2006.

34. Zanella, A., M. Mariani, G. Meola, G. Fagnani, and G. Sirchia. 1982. Phosphofructokinase (PFK) deficiency due to a catalytically inactive mutant M-type subunit. Am. J. Hematol. 12:215-225.

35. DiMauro, S., A. F. Miranda, S. Khan, K. Gitlin, and R. Friedman. 1981. Human muscle phosphoglycerate mutase deficiency: newly discovered metabolic myopathy. Science (Wash. DC). 212:12771279.

36. Tarui, S., I. Mineo, T. Shimizu, and N. Kono. 1984. Phosphofructokinase deficiency and related disorders. In Neuromuscular Disease. G. Serratrice, editor. Raven Press, New York. 71-77.

37. DiMauro, S., M. Dalakas, and A. F. Miranda. 1983. Phosphoglycerate kinase deficiency: another cause of recurrent myoglobinuria. Ann. Neurol. 13:11-19.

38. Kanno, T., K. Suda, I. Takeuchi, S. Kanda, N. Honda, Y. Nishimura, and K. Oyama. 1980. Hereditary deficiency of lactate dehydrogenase M-subunit. Clin. Chim. Acta. 108:267-276. 